\title{
Diet quality as measured by the Diet Quality Index-International is associated with prospective changes in body fat among Canadian children
}

\author{
Solmaz Setayeshgar ${ }^{1}$, Katerina Maximova ${ }^{1, *}$, John Paul Ekwaru ${ }^{1}$, Katherine Gray-Donald ${ }^{2}$, \\ Mélanie Henderson ${ }^{3,4}$, Gilles Paradis ${ }^{2,5}$, Angelo Tremblay ${ }^{6}$ and Paul Veugelers ${ }^{1}$ \\ ${ }^{1}$ School of Public Health, University of Alberta, Edmonton, 3-268 Edmonton Clinic Health Academy, Edmonton, \\ Alberta, Canada, T6G 1C9: ${ }^{2}$ Department of Epidemiology, Biostatistics and Occupational Health, McGill University, \\ Montréal, Québec, Canada: ${ }^{3}$ Centre Hospitalier Universitaire (CHU) Sainte-Justine Research Centre, University of \\ Montréal, Montréal, Québec, Canada: ${ }^{4}$ Department of Pediatrics, University of Montréal, Montréal, Québec, \\ Canada: ${ }^{5}$ Institut national de santé publique du Québec (INSPQ), Montréal, Québec, Canada: ${ }^{6}$ Division of \\ Kinesiology (PEPS), Laval University, Québec City, Québec, Canada
}

Submitted 8 April 2016: Final revision received 29 July 2016: Accepted 3 August 2016: First published online 23 September 2016

\begin{abstract}
Objective: To quantify the association of dietary quality with prospective changes in adiposity.

Design: Children participating in the QUALITY (QUebec Adipose and Lifestyle InvesTigation in Youth) study underwent examination at baseline and at 2-year follow-up. Dietary quality was assessed by the Diet Quality Index-International (DQII) using three non-consecutive $24 \mathrm{~h}$ diet recalls at baseline. The DQII has four main categories: dietary adequacy, variety, moderation and overall balance. Fat mass index (FMI; [fat mass (kg)]/[height $(\mathrm{m})]^{2}$ ), central FMI (CFMI; [trunk fat mass $(\mathrm{kg})] /[\text { height }(\mathrm{m})]^{2}$ ), percentage body fat (\%BF; [total fat mass $\left.(\mathrm{kg})\right] /[$ total mass $(\mathrm{kg})])$ and percentage central BF (\%CBF; [trunk fat mass $(\mathrm{kg})] /[$ total mass $(\mathrm{kg})]$ ) were assessed through dual-energy X-ray absorptiometry.

Setting: Children were selected from schools in the greater Montreal, Sherbrooke and Quebec City metropolitan areas between 2005 and 2008, Quebec, Canada. Subjects: A total of 546 children aged 8-10 years, including 244 girls and 302 boys. Results: Regression analysis adjusting for age, sex, energy intake, physical activity and Tanner stage revealed that every 10-unit improvement in overall DQII score was associated with lower gain in CFMI $(\beta=-0 \cdot 08 ; 95 \% \mathrm{CI}-0 \cdot 17,-0 \cdot 003)$ and $\% \mathrm{BF}$ $(\beta=-0.55 ; 95 \% \mathrm{CI}-1 \cdot 08,-0 \cdot 02)$. Each unit improvement in dietary adequacy score was associated with lower gain in FMI $(\beta=-0.05 ; 95 \%$ CI $-0 \cdot 08,-0 \cdot 008)$, CFMI $(\beta=-0 \cdot 03$; $95 \%$ CI $-0 \cdot 05,-0 \cdot 007), \% \mathrm{BF}(\beta=-0 \cdot 15 ; 95 \% \mathrm{CI}-0 \cdot 28,-0 \cdot 03)$ and $\% \mathrm{CBF}(\beta=-0 \cdot 09 ; 95 \% \mathrm{CI}-0 \cdot 15,-0 \cdot 02)$.

Conclusions: Promotion of dietary quality and adequacy may reduce weight gain in childhood and prevent chronic diseases later in life.
\end{abstract}

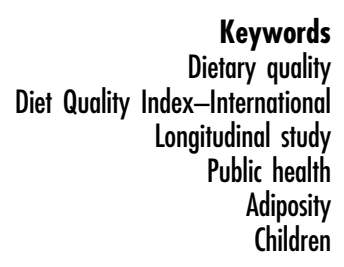

Chronic diseases in adulthood have their genesis in childhood $^{(1,2)}$. Obesity in childhood and adolescence, characterized by excessive accumulation of TAG fatty acids within adipose tissue, is a strong risk factor for several chronic diseases in adulthood ${ }^{(3)}$. Since the 1980s, there has been a remarkable rise in the prevalence of overweight and obesity among children and adolescents in developed countries $^{(4)}$. In Canada, the prevalence of overweight and obesity among youth aged 12-17 years doubled between $1978 / 79^{(5)}$ and $2009-2011^{(6)}$, and $30 \%$ of children were considered overweight or obese in 2009-2011 ${ }^{(6)}$.
Diet composition and energy intake have an important role in the deposition of $\mathrm{fat}^{(7,8)}$. Studies have revealed that adiposity occurs primarily with diets that are high in fat, high in sugar and low in fibre ${ }^{(8-10)}$. The chronic imbalance between dietary intake and oxidation of fat may lead to increases in the number and size of adipocytes ${ }^{(11)}$. Conversely, supplementation with multivitamins and minerals has recently been shown to reduce appetite and thereby body weight and fat mass ${ }^{(12,13)}$, highlighting the need to consider a broader spectrum of dietary factors rather than fat, sugar and fibre only. 
Various investigators have sought to capture the broader spectrum of dietary factors into a single index to represent dietary quality ${ }^{(14)}$. For example, the Healthy Eating Index summarized twelve food components into two dietary categories of adequacy and moderation ${ }^{(15)}$, and was recently updated to align with the key dietary recommendations of the 2010 Dietary Guidelines for Americans ${ }^{(16)}$. The Diet Quality Index-International (DQII) considers a spectrum of dietary variety, adequacy, moderation and overall balance, and was developed to allow for international comparisons and to assess the risk for chronic disease $^{(17)}$. Such indices have been utilized in a limited number of studies of dietary quality and adiposity in children and adolescents ${ }^{(18-22)}$. No study has examined the association of dietary quality and prospective changes in adiposity. For the present study, we hypothesize that children with better dietary quality will gain less body fat over time.

\section{Methods}

\section{Study population and procedures}

Participants were drawn from the QUALITY (QUebec Adipose and Lifestyle InvesTigation in Youth) cohort, a familial study on the biological, genetic, behavioural, psychosocial and environmental determinants of obesity and cardiometabolic risk factors in Caucasian children and their evolution from childhood to adulthood ${ }^{(23)}$. Families were recruited through schools in the greater Montreal, Sherbrooke and Quebec City metropolitan areas between 2005 and 2008. Eligible families comprised a child aged 8-10 years at cohort inception and biological parents, at least one of whom was obese (BMI $\geq 30.0 \mathrm{~kg} / \mathrm{m}^{2}$ and/or waist circumference $\geq 88 \mathrm{~cm}$ for women or $\geq 102 \mathrm{~cm}$ for men $\left.{ }^{(24)}\right)$. Children were excluded if they: (i) had type 1 or 2 diabetes; (ii) had any serious illness, psychological condition or cognitive disorder; (iii) were taking antihypertensive medication or steroids; and (iv) were following a very restricted diet $(<2510 \mathrm{~kJ} / \mathrm{d}(<600 \mathrm{kcal} / \mathrm{d}))$. In 2005-2008, 630 children underwent comprehensive baseline examinations at the Clinical Research Units of either the Centre Hospitalier Universitaire (CHU) SainteJustine (Montreal) or the Institut universitaire de cardiologie et de pneumologie de Québec (IUCPQ) (Quebec City). In 2008-2011, 564 (89\%) children had their first follow-up study visit.

\section{Measurements}

Dietary quality

Dietary intake was assessed through three telephoneadministered $24 \mathrm{~h}$ diet recalls on non-consecutive days (two weekdays and a weekend day) following the baseline clinic visit. After interviewing the child, trained dietitians asked a parent for details on food preparation and recipes. All three recalls were collected within 12 weeks of the baseline clinic visit; $98 \%$ of participants had three recalls and $2 \%$ had two recalls. Foods reported on the $24 \mathrm{~h}$ diet recalls were entered into the CANDAT nutrient analysis software (Godin London Inc., London, ON, Canada) and converted to nutrients using the $2007 \mathrm{~b}$ Canadian Nutrient File. Data were entered and verified by trained data-entry staff and every tenth entry was audited for accuracy by a research dietitian. Age- and sex-specific dietary recommendations were used to calculate the DQII score $^{(17,25)}$. The DQII has been used previously as a measure of dietary quality for children in Canada ${ }^{(26-28)}$, the $\mathrm{USA}^{(17)}$, China ${ }^{(17)}$ and Korea ${ }^{(28)}$. It is a summary measure of dietary quality representing four categories of the diet, including variety, adequacy, moderation and overall balance. The overall DQII score constitutes the sum of the scores for each of these four categories and ranges from 0 to 100 (where $0=$ the poorest and $100=$ the highest dietary quality). Dietary variety (score 0 to 20) captures diversity in food choices and protein sources. Dietary adequacy (score 0 to 40) captures the adequate intake of food groups and nutrients (vegetables, fruit, grains, fibres, proteins, Fe, Ca and vitamin C). Dietary moderation (score 0 to 30) is scored on the basis of intake of total fat, saturated fat, cholesterol, $\mathrm{Na}$ and empty calorie foods. Lastly, overall balance (score 0 to 10) captures the proportion of energy from carbohydrates, protein and fat, as well as the fatty acid composition, according to accepted general guidelines for the proportion of energy from carbohydrate, protein, fat, and fat composition. More detail regarding the DQII can be found elsewhere ${ }^{(17)}$.

\section{Adiposity}

Fat mass was determined by dual-energy X-ray absorptiometry (Prodigy Bone Densitometer System, DF + 14664; GE Lunar Corporation, Madison, WI, USA) ${ }^{(29)}$. Measurements were taken with the child in the supine position on the scanning table, beginning at the top of the head and moving in a rectilinear pattern down the body to the feet. None of the participants required sedation. The adiposity measures of total and central body fat were computed as follows: percentage body fat $(\% \mathrm{BF})=[$ total fat mass $(\mathrm{kg})] /$ [total mass $(\mathrm{kg})]$ and percentage central body fat (\%CBF) $=[$ trunk fat mass $(\mathrm{kg})] /[$ total mass $(\mathrm{kg})]$, respectively ${ }^{(29)}$. Fat mass index $(\mathrm{FMI})=[$ fat mass $(\mathrm{kg})] /[\text { height }(\mathrm{m})]^{2}$ and central fat mass index $(\mathrm{CFMI})=[$ trunk fat mass $(\mathrm{kg})] /[\text { height }(\mathrm{m})]^{2}$ were estimated to account for differences in height ${ }^{(30)}$.

\section{Anthropometrics}

Anthropometric measurements were taken with the child dressed in light indoor clothing without shoes, using a calibrated stadiometer for height (measured at maximal inspiration) and an electronic scale for weight. Measurements were performed according to standardized protocols in duplicate or triplicate if the first two measurements differed by more than $0.2 \mathrm{~cm}$ for height or $0.2 \mathrm{~kg}$ for weight, and the two closest measures were averaged ${ }^{(31,32)}$. BMI was calculated as [weight $(\mathrm{kg})] /[\text { height }(\mathrm{m})]^{2}$. 
BMI percentiles and $Z$-scores were calculated according to the 2000 US Centers for Disease Control and Prevention growth chart reference values ${ }^{(33)}$. A child was categorized as being thin/normal weight, overweight or obese according to the cut-offs for BMI generated by the International Obesity Task Force for 2-18-year-olds ${ }^{(34)}$.

\section{Potential confounders}

Sex and baseline values of age, pubertal maturation, physical activity and total energy intake, as well as changes in pubertal maturation and changes in physical activity between baseline and 2-year follow-up, were considered as potential confounders of the association between diet quality and changes in body fat. Pubertal maturation was assessed by trained nurses, who assigned a Tanner stage according to pubic hair development in boys and breast and pubic hair development in girls ${ }^{(35,36)}$. Changes in Tanner stage between baseline and 2-year follow-up visits were categorized into two groupings (no change $v$. increase). Physical activity was measured using $7 \mathrm{~d}$ accelerometry (ActiGraph LS 7164 activity monitor; ActiGraph LLC, Pensacola, FL, USA) in the week following the clinic visit. Children were instructed to wear the accelerometer during daytime, except during bathing and aquatic activities. Days with observation of $10 \mathrm{~h}$ or more of wear time were considered in the analysis ${ }^{(37)}$. Non-wear time was determined as at least sixty consecutive minutes of zero counts, with allowance for 1 to $2 \mathrm{~min}$ of counts between 0 and $100^{(38)}$. Moderate-intensity physical activity (2296 to 4011 counts/min) and vigorous-intensity physical activity ( $\geq 4012$ counts/min) were combined into one single category ${ }^{(37)}$. Moderate-tovigorous physical activity (MVPA) was categorized into two categories: $<60 \mathrm{~min} / \mathrm{d} v$. $\geq 60 \mathrm{~min} / \mathrm{d}$ of $\geq 2296$ counts/ min based on current guidelines ${ }^{(39)}$. Changes in MVPA between baseline and 2-year follow-up visits were categorized into three groupings (no change, increase to $\geq 60 \mathrm{~min} \mathrm{MVPA} / \mathrm{d}$, decrease to $<60 \mathrm{~min} \mathrm{MVPA} / \mathrm{d}$ ).

\section{Statistical analysis}

The present study is based on 546 children who had complete data at baseline and follow-up visits (302 boys and 244 girls). Compared with these 546 children, those lost to follow-up or with incomplete dietary information were similar with respect to total body fat, central body fat and BMI. Differences in children's characteristics between baseline and follow-up were tested using the paired $t$ test or the $\chi^{2}$ test. The distribution of DQII and each of its categories was summarized using means, medians and interquartile ranges. Changes in body fat according to DQII were depicted using the Lowess curves ${ }^{(40)}$ and leastsquares regression lines. We analysed the relationship between DQII at baseline and the 2-year change in adiposity and anthropometric outcomes (BMI, FMI, CFMI, $\% \mathrm{BF}, \% \mathrm{CBF}$ ) using multivariable linear regression models while adjusting for sex, baseline values of age, outcome variables, Tanner stage, total energy intake, physical activity, as well as change in Tanner stage and change in physical activity between baseline and follow-up. All the outcome and exposure variables except for overall balance were analysed as continuous variables. Overall balance scores were positively skewed, with $74 \%$ of the children having a score of 0 and the remainder having a score $>2$ (there were no children with a sore between 0 and 2). We therefore dichotomized overall balance to compare scores $\geq 2$ with scores $<2$. All analyses were completed using the statistical software package Stata version 13. Statistical significance was set at $P<0 \cdot 05$.

\section{Results}

Of the 546 participants with complete information, 244 (45\%) were girls and 302 (55\%) were boys. At baseline, children were on average 9.6 years of age and at follow-up 11.6 years of age (Table 1 ). Body fat indices and BMI increased during the 2-year follow-up. Over 2 years, FMI and CFMI increased on average by $18 \%$ and $22 \%$, and $\% \mathrm{BF}$ and $\% \mathrm{CBF}$ increased by $9 \%$ and $13 \%$, respectively (Table 1). These increases in total and central body fatness were not reflected in prospective changes in BMI $Z$-score or the proportion of children classified as thin/normal weight, overweight and obese (Table 1).

Table 1 Characteristics at baseline and 2-year follow-up of 546 Canadian children (244 girls and 302 boys) participating in the QUALITY (QUebec Adipose and Lifestyle InvesTigation in Youth) study

\begin{tabular}{|c|c|c|c|c|}
\hline \multirow[b]{2}{*}{ Variable } & \multicolumn{2}{|c|}{ Baseline } & \multicolumn{2}{|c|}{ Follow-up } \\
\hline & Mean & SD & Mean & SD \\
\hline Age (years)† & $9 \cdot 6^{\star \star *}$ & 0.9 & $11 \cdot 6^{\star \star \star}$ & 0.9 \\
\hline BMI Z-score $†$ & 0.7 & 1.0 & 0.7 & $1 \cdot 1$ \\
\hline BMl $\left(\mathrm{kg} / \mathrm{m}^{2}\right) \dagger$ & $19 \cdot 4^{\star \star \star}$ & 4.2 & $21 \cdot 1^{\star \star \star}$ & 4.9 \\
\hline Fat mass index $\left(\mathrm{kg} / \mathrm{m}^{2}\right) \dagger$ & $5 \cdot 4^{\star \star \star}$ & $3 \cdot 3$ & $6 \cdot 3^{\star \star \star}$ & $3 \cdot 2$ \\
\hline $\begin{array}{l}\text { Central fat mass index } \\
\left(\mathrm{kg} / \mathrm{m}^{2}\right) \dagger\end{array}$ & $2 \cdot 3^{\star \star \star}$ & $1 \cdot 7$ & $2 \cdot 8^{\star \star \star}$ & 1.9 \\
\hline$\%$ Body fat $\dagger$ & $26 \cdot 0^{\star \star \star}$ & $10 \cdot 7$ & $28 \cdot 3^{\star \star \star}$ & $10 \cdot 8$ \\
\hline \multirow[t]{2}{*}{$\%$ Central body fat $†$} & $11 \cdot 0^{\star \star \star}$ & $5 \cdot 6$ & $12 \cdot 4^{\star \star \star}$ & $5 \cdot 7$ \\
\hline & $n$ & $\%$ & $n$ & $\%$ \\
\hline \multicolumn{5}{|l|}{ Weight status $\ddagger$} \\
\hline Normal & 326 & 59.7 & 329 & $60 \cdot 3$ \\
\hline Overweight & 131 & $24 \cdot 0$ & 133 & 24.4 \\
\hline Obese & 89 & $16 \cdot 3$ & 84 & $15 \cdot 4$ \\
\hline MVPA <60 min/d $\ddagger$ & $328^{\star \star \star}$ & $67 \cdot 6$ & $343^{\star \star \star}$ & $79 \cdot 8$ \\
\hline \multicolumn{5}{|l|}{ Tanner stage $\S>1 \ddagger$} \\
\hline Girls & $87^{\star \star \star}$ & $35 \cdot 7$ & $200^{\star \star \star}$ & $82 \cdot 3$ \\
\hline Boys & $24^{\star \star *}$ & $7 \cdot 9$ & $163^{* \star \star}$ & 5.5 \\
\hline Total energy intake (kJ/d) & 7073 & 1663 & NAll & \\
\hline Total energy intake $(\mathrm{kcal} / \mathrm{d})$ & $1690 \cdot 5$ & 397.4 & NAll & \\
\hline
\end{tabular}

MVPA, moderate-to-vigorous physical activity; NA, not assessed. ${ }^{\star} P<0.001$

†Differences between baseline and 2-year follow-up tested using the paired $t$ test.

‡Differences between baseline and 2-year follow-up tested using the $x^{2}$ test. §Tanner stage values ranged from 1 to 4 at baseline and from 1 to 5 at follow-up.

IIData were not available at follow-up. 
Overall DQII score ranged from 34 to 75 and was approximately the same among boys and girls (58 v. 57 , respectively). Table 2 shows that, on average, participants had relatively high scores for dietary variety (15 out of 20) and adequacy (30 out of 40) but had substantially lower scores for moderation (12 out of 30) and overall balance (1 out of 10). These striking differences in the distribution of the overall DQII score and its categories, expressed as percentages, are depicted in Fig. 1.

Table 2 Average Diet Quality Index-International (DQII) scores in 546 Canadian children (244 girls and 302 boys) participating in the QUALITY (QUebec Adipose and Lifestyle InvesTigation in Youth) study

\begin{tabular}{|c|c|c|c|}
\hline DQII category/component & Score range & Mean & $\mathrm{SD}$ \\
\hline Overall DQII & $0-100$ & 57.9 & $7 \cdot 2$ \\
\hline Variety & $0-20$ & $15 \cdot 5$ & 3.3 \\
\hline Overall food group variety & $0-15$ & $12 \cdot 4$ & 2.6 \\
\hline $\begin{array}{l}\text { Within-group variety for } \\
\text { protein sources }\end{array}$ & $0-5$ & $3 \cdot 1$ & $1 \cdot 2$ \\
\hline Adequacy & $0-40$ & 29.7 & 3.7 \\
\hline Vegetables group & $0-5$ & $2 \cdot 3$ & 1.3 \\
\hline Fruit group & $0-5$ & 3.4 & 1.6 \\
\hline Grains group & $0-5$ & 3.7 & 1.0 \\
\hline Fibres & $0-5$ & $2 \cdot 3$ & 0.7 \\
\hline Proteins & $0-5$ & $5 \cdot 0$ & 0.1 \\
\hline $\mathrm{Fe}$ & $0-5$ & 4.9 & 0.3 \\
\hline $\mathrm{Ca}$ & $0-5$ & $3 \cdot 2$ & 1.0 \\
\hline Vitamin C & $0-5$ & $4 . \overline{9}$ & 0.6 \\
\hline Moderation & $0-30$ & 11.9 & 4.4 \\
\hline Total fat & $0-6$ & 1.0 & 1.4 \\
\hline Saturated fat & $0-6$ & 0.9 & 1.5 \\
\hline Cholesterol & $0-6$ & 5.4 & 1.4 \\
\hline $\mathrm{Na}$ & $0-6$ & 4.3 & $2 \cdot 0$ \\
\hline Empty calorie foods & $0-6$ & 0.3 & 0.9 \\
\hline Overall balance & $0-10$ & 0.7 & 1.4 \\
\hline Macronutrient ratio & $0-6$ & 0.5 & $1 \cdot 1$ \\
\hline Fatty acid ratio & $0-4$ & 0.2 & 0.7 \\
\hline
\end{tabular}

Figure 2 presents scatter plots of DQII scores in relation to changes in adiposity and reveals smaller 2-year increases in body fat for participants with higher baseline DQII scores. The gradient seems to approximate linearity because the depicted Lowess curves and leastsquares regression lines are similar (Fig. 2). Table 3 presents the estimated magnitude of the changes in adiposity for every 10-unit improvement in the overall DQII score and 1-unit improvement in DQII categories. After adjusting for all confounders, every 10-units improvement in the overall DQII score was associated with lower gain in CFMI $(\beta=-0 \cdot 08 ; 95 \% \mathrm{CI}-0 \cdot 17,-0 \cdot 003)$ and $\% \mathrm{BF}(\beta=-0.55 ; 95 \% \mathrm{CI}-1.08,-0.02)$ Dietary adequacy was associated with all body fat indicators after adjusting for confounders. Every unit improvement in dietary adequacy score was associated with lower gain in FMI $(\beta=-0.05 ; 95 \%$ CI $-0 \cdot 08,-0 \cdot 008)$, CFMI $(\beta=-0 \cdot 03$; $95 \%$ CI $-0.05,-0 \cdot 007), \% \mathrm{BF}(\beta=-0 \cdot 15 ; 95 \%$ CI $-0 \cdot 28$, $-0.03)$ and $\% \operatorname{CBF}(\beta=-0.09 ; 95 \% \mathrm{CI}-0 \cdot 15,-0 \cdot 02)$. None of the other DQII categories (variety, moderation and overall balance) were associated with 2-year changes in adiposity. Finally, neither the DQII nor any of its categories were associated with changes in BMI over 2 years.

\section{Discussion}

In the present study, we demonstrated that children with poor dietary quality and particularly poor dietary adequacy were on a trajectory of greater adiposity gain relative to children with better dietary quality. We observed associations of dietary quality with CFMI and $\% \mathrm{BF}$, independent of sex, age, total energy intake, physical activity and Tanner stage, but not with FMI, \%CBF and

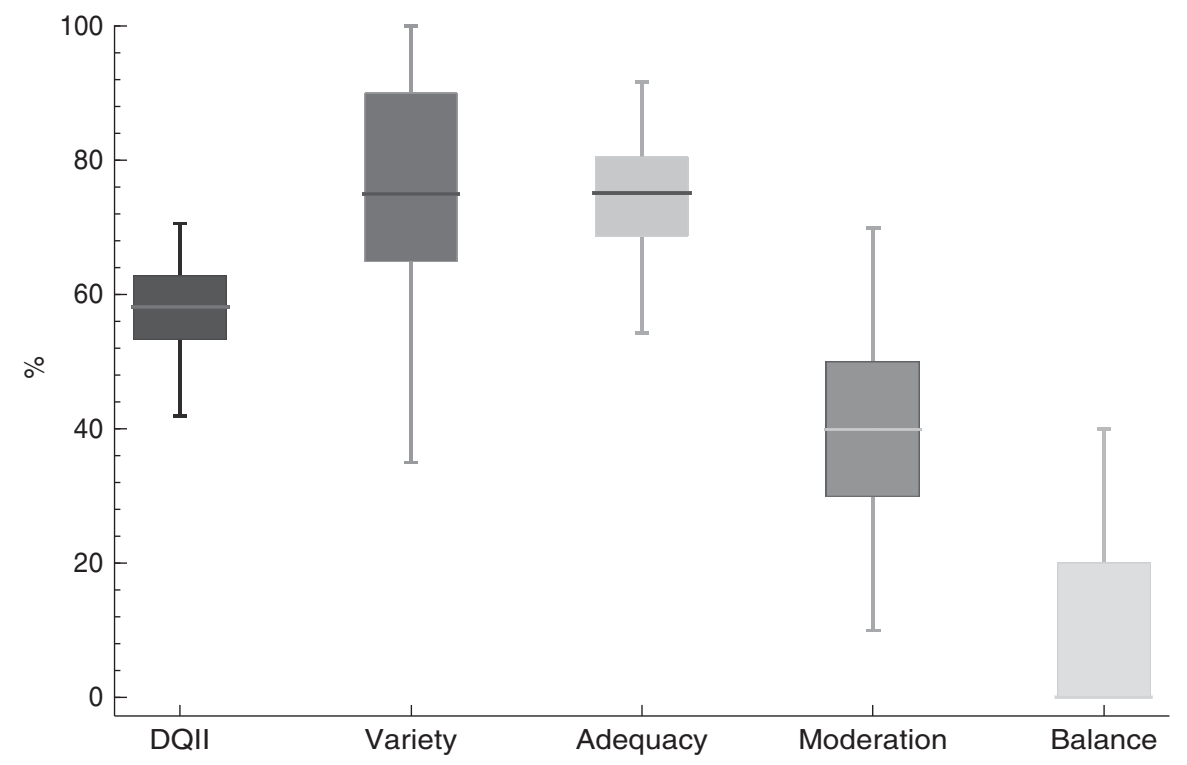

Fig. 1 Box plots of overall Diet Quality Index-International (DQII) and its categories in 546 Canadian children (244 girls and 302 boys) participating in the QUALITY (QUebec Adipose and Lifestyle InvesTigation in Youth) study. The line within the boxes represents the median, the height of the boxes shows the interquartile range, and the whiskers extend to the 2.5 and 97.5 percentiles of the distribution 

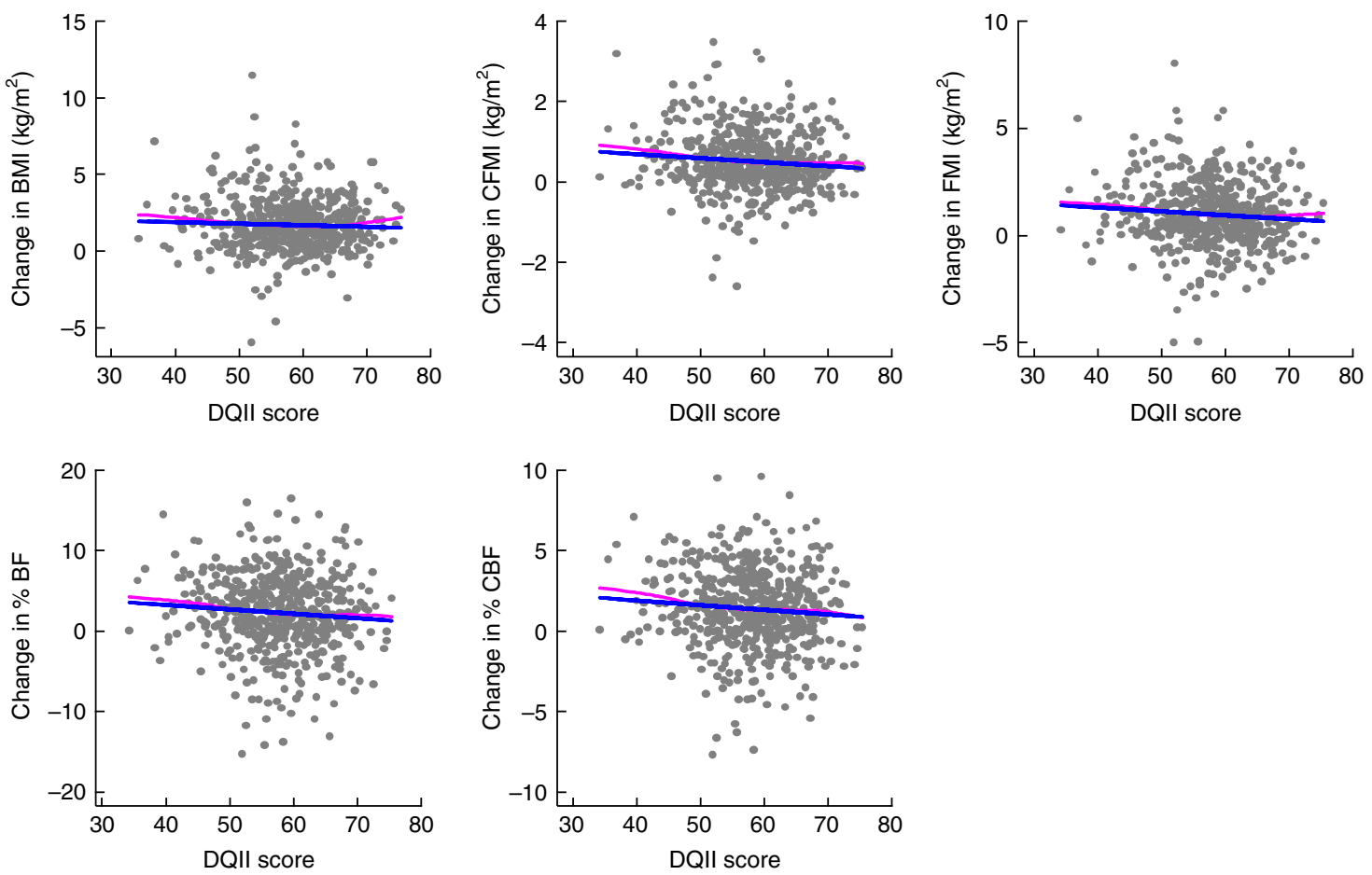

Fig. 2 Association of Diet Quality Index-International (DQII) score with changes in adiposity between baseline and 2-year follow-up in 546 Canadian children (244 girls and 302 boys) participating in the QUALITY (QUebec Adipose and Lifestyle InvesTigation in Youth) study: —_ Loess (local regression of the association between diet quality and changes in adiposity and BMI); — , linear least-squares regression of the association between diet quality and changes in adiposity and BMI (CFMI, central fat mass index; FMI, fat mass index; \%BF, percentage body fat; \%CBF, percentage central body fat)

BMI. We observed statistically significant associations of dietary adequacy, but not of dietary variety, moderation and balance, with FMI, CFMI, \%BF and \%CBF.

With an average DQII score of 58 , the dietary quality of the children participating in the QUALITY study appeared slightly lower than that reported in prior studies that have used this measure. The DQII scores of 61 and 62 were observed for grade 5 students in the Canadian provinces of Nova Scotia ${ }^{(26)}$ and Alberta $^{(27)}$, respectively. Further, average DQII scores of 67, 60 and 59 have been reported for elementary students in Korea ${ }^{(28)}$ and for nationally representative samples of children in China and the $\mathrm{USA}^{(17)}$, respectively. The relatively poor dietary quality seems consistent with the observation that QUALITY participants are more likely overweight or obese and more likely to have a poor lipid profile relative to a representative sample of Quebec children ${ }^{(23)}$. This is likely a consequence of the inclusion criterion that limited study eligibility/enrolment to children of obese parents. The relatively high values for dietary variety and adequacy in comparison with the low values for dietary moderation and overall balance in the present study (Fig. 1) were also reported for the American population ${ }^{(17)}$.

The relationship of dietary quality and adiposity has not been extensively investigated among children. A prospective study in the UK found a strong association between poor dietary quality and higher total fat mass $Z$-scores among children below the age of 6 years ${ }^{(19)}$.
A cross-sectional US study among adolescents utilized the Healthy Eating Index and reported negative associations with both $\% \mathrm{BF}$ and percentage abdominal fat ${ }^{(21)}$. A Greek cross-sectional study utilized the E-KINDEX tool to assess dietary quality among children (mean age: $10 \cdot 7$ years) and reported higher dietary quality to be associated with lower $\% \mathrm{BF}^{(22)}$. With respect to $\mathrm{BMI}$, three studies, including a cohort study in Australia ${ }^{(18)}$ that followed participants from birth to adolescence, the prospective UK study ${ }^{(19)}$ and a cross-sectional study among grade 5 children in Nova Scotia ${ }^{(20)}$, reported no associations of dietary quality with BMI or excess body weight. An Australian cohort study among children (5-12 years at baseline) in socioeconomically disadvantaged neighbourhoods revealed an association between dietary quality and BMI $Z$-scores among those children who were overweight but not among those with normal body weight ${ }^{(41)}$. Similarly, previous studies $^{(19,21,22)}$ reported associations of dietary quality with actual measures of body fat rather than BMI in childhood or adolescence. Two years of follow-up may be too short to expect changes in body fat to translate into differences in body weight categories or BMI in this age group. Studies with longer follow-up may reveal such differences.

The present study examined the importance of dietary quality for prospective changes in adiposity, which had not been previously reported in children and youth. Our findings are consistent with the studies conducted in the $\mathrm{UK}^{(19)}$, $\mathrm{USA}^{(21)}$ and Greece ${ }^{(22)}$, with an additional finding 


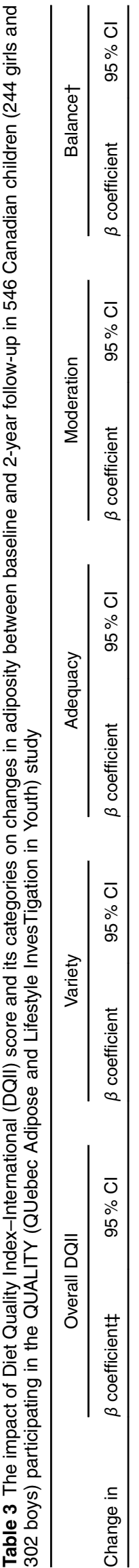

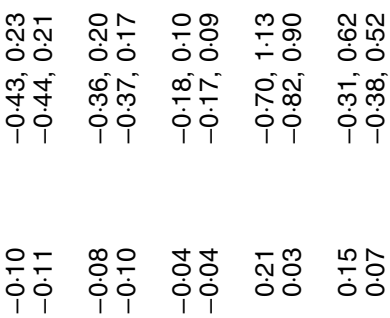

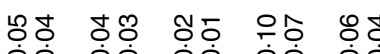

O० 00 0ं 0ं 0ं

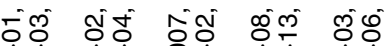

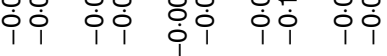

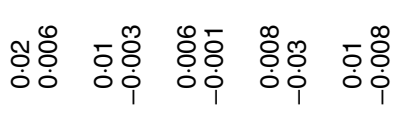

\&े

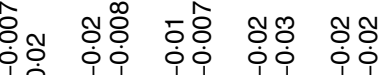

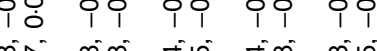

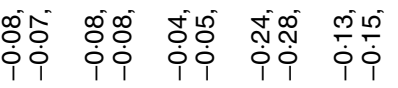

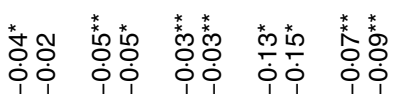

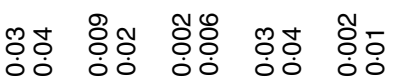

ध่

i

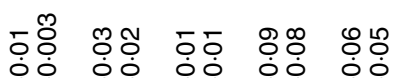

íl

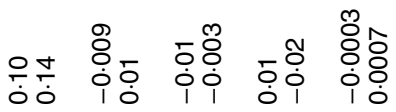

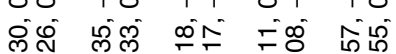

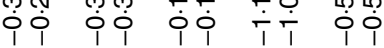

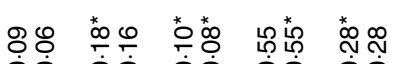

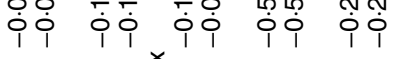<smiles>[Mg][TeH]</smiles>

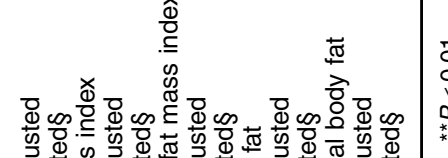

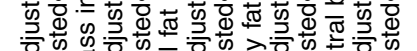

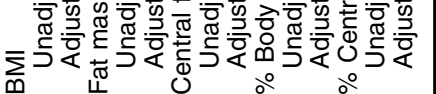

of an association of dietary quality with central body fat. The magnitude of changes in total and central body fat that were associated with the overall DQII score seems comparable with those of others ${ }^{(18)}$. Although the magnitude of changes is small, the cumulative impact over time may be substantial.

Dietary adequacy captures the adequate consumption of fruit and vegetables, grains, protein, fibre, $\mathrm{Fe}, \mathrm{Ca}$ and vitamin $C^{(17,42)}$. The present study revealed that dietary adequacy was associated with all adiposity indicators. This observation seems consistent with the concept that adequacy of multiple micronutrients and macronutrients, rather than adequacy of a single nutrient, is essential to good health ${ }^{(14)}$. In the present study, we did not reveal significant associations of dietary variety, moderation and balance with adiposity. The explanation of this may be twofold. First, the association between dietary quality and adiposity was mostly driven by adequacy. Second, nutrition research has a long history of studying adequacy ${ }^{(43)}$, which has led to good definitions and quantifications of adequacy ${ }^{(44)}$. Inaccuracies in the definitions and quantifications of variety, moderation and balance may have hampered our ability to observe statistically significant associations.

\section{Strengths and limitations}

The present study benefits from several strengths including high retention rate at follow-up (89\%), objective measurement of body fat through dual-energy X-ray absorptiometry and physical activity through accelerometer, as well as directly measured height and weight. Dual-energy X-ray absorptiometry is increasingly accepted as a reference method to measure body composition ${ }^{(45)}$. Each participant completed two or three $24 \mathrm{~h}$ dietary recalls as a single recall may fail to capture the usual intake of individuals ${ }^{(46)}$. However, our study has some limitations. It is not known how representative changes over a period of 2 years are for longer-term weight gain and risk of chronic diseases. The generalizability of our findings may be limited to Caucasian children with a parental history of obesity, higher socio-economic status, and who are at risk for overweight or obesity. No dietary data were collected at the 2-year follow-up visit which prevented us from examining changes in dietary intake over time.

\section{Conclusion}

We observed an inverse association of dietary quality and dietary adequacy with changes in total body fat and central body fat independent of sex, age, total energy intake, physical activity and Tanner stage among children. Therefore, the present findings support preventive initiatives aimed at enhancing the quality of the diet and particularly the adequate intakes of nutrients as a means to reduce the societal burden of excess body weight. Health promotion to date has mostly focused on the reduction of dietary fat 
and added sugar as strategies to promote healthy body weight. The observations of the present study make a case for the promotion of dietary quality and adequacy as a strategy to achieve healthier body weight and reduce the development of chronic diseases in the long term ${ }^{(47,48)}$.

\section{Acknowledgements}

Acknowledgements: Dr Marie Lambert (July 1952-February 2012), paediatric geneticist and researcher, initiated the QUALITY cohort. Her leadership and devotion to QUALITY will always be remembered and appreciated. The cohort integrates members of TEAM PRODIGY, an inter-university research team including Université de Montréal, Concordia University, INRS-Institute-Armand Frappier, Université Laval and McGill University. The research team is grateful to all the children and their families who took part in this study, as well as the technicians, research assistants and coordinators involved in the QUALITY cohort project. Financial support: The QUALITY cohort is funded by the Canadian Institutes of Health Research (grant numbers OHF-69442, NMD-94067, MOP-97853, MOP-119512); the Heart and Stroke Foundation of Canada (grant number PG-040291); and Fonds de la Recherche en Santé du Québec. K.M. holds a Career Development Award in Prevention Research funded by the Canadian Cancer Society (grant number 702936). M.H. holds a Fonds de Recherche en Santé du Québec Junior 1 salary award. The present analysis was funded through the Collaborative Research and Innovation Opportunities (CRIO) Team programme from Alberta Innovates-Health Solutions (AIHS). The funders had no role in the design, analysis or writing of this article. Conflict of interest: There is no conflict of interest. Authorship: M.H., G.P., A.T. and K.G.-D are the Principal Investigators of the QUALITY study. S.S., P.V. and K.M. conceived the research idea. S.S. conducted the statistical analysis and drafted the manuscript. S.S., P.V., K.M. and J.E. interpreted the statistical analysis. All authors critically reviewed and provided feedback to the draft manuscript. All authors read and approved the final manuscript. Ethics of human subject participation: All children provided assent and their parents provided signed informed consent. QUALITY protocols have received approval from the Institutional Ethics Review Board at the CHU Sainte-Justine and Laval University. The Institutional Ethics Review Board at the University of Alberta approved the current study.

\section{References}

1. McMahan CA, McGill HC, Gidding SS et al. (2007) PDAY risk score predicts advanced coronary artery atherosclerosis in middle-aged persons as well as youth. Atherosclerosis 190, 370-377.

2. McGill HC, McMahan CA, Herderick EE et al. (2000) Origin of atherosclerosis in childhood and adolescence. Am J Clin Nutr 72, 5 Suppl., 1307S-1315S.
3. Reilly J \& Kelly J (2010) Long-term impact of overweight and obesity in childhood and adolescence on morbidity and premature mortality in adulthood: systematic review. Int J Obes (Lond) 35, 891-898.

4. Ng M, Fleming T, Robinson M et al. (2014) Global, regional, and national prevalence of overweight and obesity in children and adults during 1980-2013: a systematic analysis for the Global Burden of Disease Study 2013. Lancet 384, 766-781.

5. Shields M (2006) Overweight and obesity among children and youth. Health Rep 17, 27-42.

6. Statistics Canada (2012) Body Mass Index of Canadian Children and Youth, 2009 to 2011. Catalogue no. 82-625X2011001. Ottawa, ON: Statistics Canada.

7. Frayn KN, Coppack SW \& Potts JL (1992) Effect of diet on human adipose tissue metabolism. Proc Nutr Soc 51, 409-418.

8. Nelson LH \& Tucker LA (1996) Diet composition related to body fat in a multivariate study of 203 men. J Am Diet Assoc 96, 771-777.

9. Kromhout D, Bloemberg B, Seidell J et al. (2001) Physical activity and dietary fiber determine population body fat levels: the Seven Countries Study. Int J Obes Relat Metab Disord 25, 301-306.

10. Miller WC, Niederpruem MG, Wallace JP et al. (1994) Dietary fat, sugar, and fiber predict body fat content. J Am Diet Assoc 94, 612-615.

11. Flatt JP (1995) Use and storage of carbohydrate and fat. Am J Clin Nutr 61, 4 Suppl., 952S-959S.

12. Major GC, Alarie FP, Doré J et al. (2009) Calcium plus vitamin D supplementation and fat mass loss in female very low-calcium consumers: potential link with a calciumspecific appetite control. Br J Nutr 101, 659-663.

13. Major GC, Doucet E, Jacqmain M et al. (2008) Multivitamin and dietary supplements, body weight and appetite: results from a cross-sectional and a randomised double-blind placebo-controlled study. Br J Nutr 99, 1157-1167.

14. Kourlaba G \& Panagiotakos DB (2009) Dietary quality indices and human health: a review. Maturitas 62, 1-8.

15. Kennedy ET, Ohls J, Carlson S et al. (1995) The Healthy Eating Index: design and applications. J Am Diet Assoc 95, 1103-1108.

16. Guenther PM, Casavale KO, Reedy J et al. (2013) Update of the Healthy Eating Index: HEI-2010. J Acad Nutr Diet 113, $569-580$

17. Kim S, Haines PS, Siega-Riz AM et al. (2003) The Diet Quality Index-International (DQI-I) provides an effective tool for cross-national comparison of diet quality as illustrated by China and the United States. J Nutr 133, 3476-3484.

18. Meyerkort C, Oddy WH, O'Sullivan T et al. (2012) Early diet quality in a longitudinal study of Australian children: associations with nutrition and body mass index later in childhood and adolescence. J Dev Orig Health Dis 3, 21-31.

19. Okubo H, Crozier SR, Harvey NC et al. (2015) Diet quality across early childhood and adiposity at 6 years: the Southampton Women's Survey. Int J Obes (Lond) 39, 1456-1462.

20. Kuhle S, Allen AC \& Veugelers PJ (2010) Perinatal and childhood risk factors for overweight in a provincial sample of Canadian Grade 5 students. Int J Pediatr Obes 5, 88-96.

21. Hurley KM, Oberlander SE, Merry BC et al. (2009) The healthy eating index and youth healthy eating index are unique, nonredundant measures of diet quality among lowincome, African American adolescents. J Nutr 139, 359-364.

22. Lazarou C, Panagiotakos DB \& Matalas A (2008) Development and accuracy of E-KINDEX: a novel dietary index and a self-monitoring tool that is associated with obesity status in children. J Am Diet Assoc 108, A49. 
23. Lambert M, Van Hulst A, O'Loughlin J et al. (2012) Cohort profile: the Quebec adipose and lifestyle investigation in youth cohort. Int J Epidemiol 41, 1533-1544.

24. Grundy SM, Cleeman JI, Daniels SR et al. (2005) Diagnosis and management of the metabolic syndrome: an American Heart Association/National Heart, Lung, and Blood Institute Scientific Statement. Circulation 112, 2735-2752.

25. Health Canada (2011) Eating Well with Canada's Food Guide. http://www.hc-sc.gc.ca/fn-an/food-guidealiment/order-commander/eating_well_bien_manger-eng.php (accessed September 2015)

26. Veugelers PJ, Fitzgerald AL \& Johnston E (2005) Dietary intake and risk factors for poor diet quality among children in Nova Scotia. Can J Public Health 96, 212-216.

27. Ferland A, Chu YL, Gleddie D et al. (2014) Leadership skills are associated with health behaviours among Canadian children. Health Promot Int 30, 106-113.

28. Kim MH \& Bae YJ (2010) Evaluation of diet quality of children and adolescents based on nutrient and food group intake and diet quality index-international (DQI-I). Korean J Community Nutr 15, 1-14.

29. Goran MI (1998) Measurement issues related to studies of childhood obesity: assessment of body composition, body fat distribution, physical activity, and food intake. Pediatrics 101, 505-518.

30. Freedman DS, Wang J, Maynard LM et al. (2005) Relation of BMI to fat and fat-free mass among children and adolescents. Int J Obes (Lond) 29, 1-8.

31. Lambert M, Delvin EE, Levy E et al. (2008) Prevalence of cardiometabolic risk factors by weight status in a population-based sample of Quebec children and adolescents. Can J Cardiol 24, 575-583.

32. de Onis M, Onyango AW, Van den Broeck J et al. (2004) Measurement and standardization protocols for anthropometry used in the construction of a new international growth reference. Food Nutr Bull 25, 1 Suppl., S27-S36.

33. Kuczmarski RJ, Ogden CL, Guo SS et al. (2002) 2000 CDC Growth Charts for the United States: methods and development. Vital Health Stat 11 issue 246, 1-190.

34. Cole TJ \& Lobstein T (2012) Extended international (IOTF) body mass index cut-offs for thinness, overweight and obesity. Pediatr Obes 7, 284-294.
35. Marshall WA \& Tanner JM (1969) Variations in pattern of pubertal changes in girls. Arch Dis Child 44, 291-303.

36. Marshall WA \& Tanner JM (1970) Variations in the pattern of pubertal changes in boys. Arch Dis Child 45, 13-23.

37. Trost SG, Loprinzi PD, Moore R et al. (2011) Comparison of accelerometer cut points for predicting activity intensity in youth. Med Sci Sports Exerc 43, 1360-1368.

38. Colley RC, Garriguet D, Janssen I et al. (2011) Physical activity of Canadian children and youth: accelerometer results from the 2007 to 2009 Canadian Health Measures Survey. Health Rep 22, 15-23.

39. Tremblay MS, Warburton DE, Janssen I et al. (2011) New Canadian physical activity guidelines. Appl Physiol Nutr Metab 36, 36-46.

40. Jacoby WG (2000) Loess: a nonparametric, graphical tool for depicting relationships between variables. Elect Stud $\mathbf{1 9}$, $577-613$

41. Lioret S, McNaughton SA, Cameron AJ et al. (2014) Three-year change in diet quality and associated changes in BMI among schoolchildren living in socio-economically disadvantaged neighbourhoods. Br J Nutr 112, 260-268.

42. Lee YD, Kim KW, Choi KS et al. (2016) Development of dietary pattern evaluation tool for adults and correlation with Dietary Quality Index. Nutr Res Pract 10, 305-312.

43. Wretlind A (1982) Standards for nutritional adequacy of the diet: European and WHO/FAO viewpoints. Am J Clin Nutr 36, 366-375.

44. Dhonukshe-Rutten RA, Bouwman J, Brown KA et al. (2013) EURRECA - evidence-based methodology for deriving micronutrient recommendations. Crit Rev Food Sci Nutr 53, 999-1040.

45. Nahikian-Nelms M (2011) Nutrition Therapy and Pathophysiology. Belmont, CA: Wadsworth, Cengage Learning.

46. Bingham SA (1991) Limitations of the various methods for collecting dietary intake data. Ann Nutr Metab 35, 117-127.

47. Després J-P (2012) Body fat distribution and risk of cardiovascular disease an update. Circulation 126, 1301-1313.

48. Fung C, McIsaac JL, Kuhle S et al. (2013) The impact of a population-level school food and nutrition policy on dietary intake and body weights of Canadian children. Prev Med 57, 934-940. 